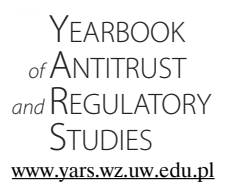

Peer-reviewed scientific periodical, focusing on legal and economic issues of antitrust and regulation. Creative Commons Attribution-No Derivative Works 3.0 Poland License.

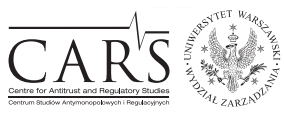

Centre for Antitrust and Regulatory Studies, University of Warsaw, Faculty of Management www.cars.wZ.uw.edu.pl

\title{
(Why) Did EU Net Neutrality Rules Overshoot the Mark? Internet, Disruptive Innovation and EU Competition Law \& Policy
}

\author{
by
}

Oles Andriychuk*

\section{CONTENTS}

I. Introduction

II. Scale of regulatory intervention

III. EU Net Neutrality Rules

IV. Parallel reality: a business model without Net Neutrality rules

V. Conclusion

\section{Abstract}

This essay raises a number of theses in support for a more liberalised approach to EU Net Neutrality rules. It offers a graded system of levels of regulatory intervention, arguing that soft Net Neutrality rules are capable of meeting all positive objectives of regulation without causing the problems generated by hard Net Neutrality rules, such as those currently in place in the EU. Hard Net Neutrality rules prevent Internet Service Providers (ISPs) from making disruptive innovations. Meanwhile, they enable some Content and Application Providers (CAPs) to monopolise many markets via (disruptive) innovations, resulting in newly established dominant positions which have, in many instances, been abused. The hypothesis of the essay is that loosening the rules on Net Neutrality would create competition between ISPs and CAPs as well as (which is even more important) between different CAPs for

* Dr Oles Andriychuk, Senior Lecturer in Internet Law, University of Strathclyde, UK; e-mail: oles.andriychuk@strath.ac.uk. I am grateful to participants of the 22nd Annual EU Competition Law and Policy Workshop Disruptive Innovation and Implications for Competition Policy (EUI, Florence, June 2017) and in particular to Bill Kovacic, Giorgio Monti, Mel Marquis and Ioannis Lianos for their inspiring thoughts and criticism on the hypothesis of this paper. The usual disclaimer applies. Article received: 8 June 2018; accepted: 25 September 2018. 
limited premium speed traffic. Such newly established competition could remedy some antitrust conundrums faced by EU competition enforcers and sectorial regulators vis-à-vis disruptive innovators in the area of electronic communications.

\section{Resume}

Cet article soulève un certain nombre de thèses en faveur d'une approche plus libéralisée aux règles de l'UE concernant la neutralité du Net. Il offre un système progressif de niveaux d'intervention réglementaire, affirmant que des règles non contraignantes de la neutralité du Net sont en mesure de répondre à tous les objectifs positifs de la réglementation sans causer les problèmes engendrés par les règles contraignantes, telles que celles actuellement en vigueur dans l'UE. Les règles contraignantes de la neutralité du Net empêchent les fournisseurs de services Internet de développer des innovations perturbatrices. Dans le même temps, ils permettent à certains fournisseurs de contenus et d'applications de monopoliser nombreux marchés via des innovations (perturbatrices), donnant ainsi lieu à des nouvelles positions dominantes, qui ont souvent fait l'objet d'abus. L'hypothèse de l'article est que desserrant les règles sur la neutralité du Net créerait la concurrence entre les fournisseurs de services Internet et les fournisseurs des contenus et d'applications, ainsi que (ce qui est encore plus important) entre les différents fournisseurs des contenus et d'applications pour le trafic de vitesse limitée premium. Cette concurrence nouvellement établie pourrait remédier à certains problèmes de concurrence soulevés par les autorités de la concurrence de l'UE et les régulateurs sectoriels vis-à-vis des innovateurs perturbateurs dans le domaine des communications électroniques.

Key words: Disruptive innovation; electronic communication; Net Neutrality; Net Prioritisation; EU Competition Law; sector specific regulation and other ex-ante regulatory tools; Internet Service Providers (ISPs) vs. Content and Application Providers (CAPs); proactive competition policy.

JEL: K21

\section{Introduction}

It would be hard to find opponents of Net Neutrality when taken in its broadest political sense. Indeed, who would argue against universal access to the Internet; information qua fundamental societal value; or the idea that everyone should have the opportunity to communicate with a global audience? The rhetoric of Net Neutrality, its conversion into a political manifesto of 'digital liberty', into an existential precondition of the Internet as such, has 
created a caricaturised image of the discussion, a dichotomised conception of 'good guys' and 'bad guys': Progress, Openness, and Inclusiveness vs. Conservatism, Narrow-mindedness, and Selfishness. The power of the slogan of Net Neutrality can perhaps be easily compared with the rhetorical omnipotence of another polysemic term 'consumer welfare'. Due not least to this effective conversion of what is primarily an economic interest into the language of political activism, human rights and public interests, the proponents of Net Neutrality have succeeded in transposing its key principles and premises into sector specific regulations on both sides of the Atlantics. However, shifted from the domain of political activism to economic reality, the issue of Net Neutrality immediately becomes much more nuanced with both parties to this debate having their stronger and weaker sides. Some of them will be addressed in this essay.

An intense discussion on Net Neutrality is often connected with another topical regulatory issue in the area of information technology: disruptive innovation. Both themes and both policies are usually seen as being mutually supportive: Net Neutrality encourages disruptive innovation, enabling risky and innovative newcomers to outperform incumbents, and this process in turn contributes to further strengthening of the idea of Net Neutrality. This essay does not share such a view. Or rather, it argues that this is only part of the story. The other side of the story has two key components: first, it claims that hard Net Neutrality rules distort disruptive innovations on the telecom side of the business; second, some of these disruptive innovations cause concern for European antitrust regulators. It is thus unclear, why such innovators should continue to receive such preferential treatment from the regulators, getting, essentially, absolute protection from competition coming from telecoms. The essay puts forward and develops several hypotheses, which seek to decompose this illusory synergy between Net Neutrality and disruptive innovation, arguing that loosening the rules on Net Neutrality, and giving Internet Service Providers (hereinafter; ISPs) more flexibility with traffic management, would strengthen inter-/ and intra-sectorial competition, which would benefit consumers, industrial growth and disruptive innovation itself.

This paper raises a rather provocative question: whether (and if so, then to what extent) the current regulatory perplexity, with which European authorities approach competition-related problems associated with disruptive technologies in the area of the Internet, has been created or at least facilitated by Net Neutrality regulation. Or perhaps less controversially: can softening the rules on Net Neutrality counterbalance the current situation by facilitating an emergence of disruptive innovators on the side of Internet Service Providers? If the answer to this question is affirmative, then it is possible to ask another, more important, question. Namely, whether the current dominance of 
disruptive innovators on the content side of the market could be challenged by the market's invisible hand; and whether ISPs could be encouraged by proactive sector specific regulation to launch/reinforce competition in this sector by triggering their key tool: traffic speed gradation.

The assumption supporting this essay is quite straightforward: if one of the key challenges of contemporary competition policy ${ }^{1}$ is in designing effective regulatory tools capable of addressing the unprecedented growth in dominance of disruptive technologies in the Internet, then a solution could possibly be offered by the leading competing industry: telecoms. Alternatively, at least that regulators should intervene in the organic competitive process between content and application providers (hereinafter; CAPs) on one side and ISPs on the other only with a particular delicacy; intervene only in a manner, not giving explicit priority to one industry over another, let alone prohibiting ISPs from taking part in disruptive innovation outright through the imposition of hard Net Neutrality rules.

An important caveat should be entered at the very outset. This essay does not advocate the view that the principle of Net Neutrality is wrong in itself or that the opposing approach - Net Prioritisation - is a panacea for the problems associated with antitrust regulation of disruptive technologies in the area of the Internet. The argument is much more modest and nuanced and it is primarily apagogical. I argue that the very nature of disruptive innovation is based on the notion of unpredictability; that it is usually created in a competitive environment similar to Hayek's 'competition qua discovery procedure', which is inherently driven by Smith's idea of 'the invisible hand'. Because disruptive innovation is by definition unpredictable and because it is driven by markets' 'spontaneous order', all/many/some of its shortcomings, which currently puzzle most antitrust regulators, should be left for the markets' self-correction. Instead of adopting this approach, regulators in the EU and US have chosen a completely different route, giving categorical priority to one industry (CAPs) over the other (ISPs), wrongly believing that disruptive innovation streams exclusively from the former, considering the latter as merely a 'dumb pipe'. Regulatory bonuses such as Net Neutrality, have given priority to the CAPs, many of whom have used it successfully to become disruptive innovators and gain positions of super-dominance in their relevant markets. In other words, regulators' unprecedented benevolence to one industry at the cost of the other has contributed substantially to the emergence of a situation wherein many disruptive innovators have themselves become a headache to antitrust authorities. Potential ISPs competitors, who could be expected to

${ }^{1}$ I use the term 'competition policy' broadly, implying traditional reactionary tools such as antitrust as well as more proactive mechanisms like mergers and ex ante sector specific regulation. 
counterbalance such super-dominance by using the mechanism of market forces, have been effectively disabled from these attempts by de iure or de facto prohibition of Net Prioritisation. Net Prioritisation is in itself an effective tool of competition, which could rearrange the whole architecture of Internet commerce - a particularly powerful proposition in a time of growing synergy and hybridisation of ISPs and CAPs across the Internet.

\section{Scale of regulatory intervention}

The variety of regulatory options can be visualised as a line with gradual levels of regulatory interference, where Level 0 is the most liberal and Level $6+$ is the most paternalistic. Current EU rules on Net Neutrality are set on Level 5B. The essay argues that they have to be moved up to Level 5A. ${ }^{2}$

Level 0 - being a genuine laissez-faire (hands off) approach with full reliance on the Schumpeterian process of creative destruction;

Level 1 - laissez-faire + contract law and public security;

Level 2 - adding also ex post antitrust rules;

Level 3 - adding also ex ante merger control;

Level 4 - adding also ex ante sector specific regulation prohibiting discrimination, throttling and other forms of traffic downgrade (soft Net Neutrality rules and respective rejection of hard Net Prioritisation rules);

Level 5 - adding also a prohibition of any type of traffic prioritisation (hard Net Neutrality rules and respective rejection of both hard and soft Net Prioritisation rules);

Level 6 and Level 6+ - various types of dirigisme or planned/command economy.

This essay explicitly differentiates between two types of conduct, which hard Net Neutrality rules respectively prohibit: reactionary and proactive.

The former (reactionary) is in general a counterproductive reaction on the part of ISPs to various disruptive initiatives launching by CAPs. The reaction is related mainly to blocking, throttling or discrimination of disruptive goods and services which threaten the established business models of the incumbents (for example VoIP vs. fixed line). Arguably, these practices could be dealt with effectively by such classical ex post antitrust tools as Articles 101; 102 and 106 TFEU, but ex ante prohibition of such conduct in the form of soft Net Neutrality rules (Level 4) does not appear to be particularly problematic.

\footnotetext{
${ }^{2}$ Infra.
} 
The latter (proactive) is a completely different mode of conduct. It refers to ISPs' exploration of (disruptive) business models using traffic prioritisation technologies as leverage. Prohibition of such practices is enacted by hard Net Neutrality rules (Level 5B). Its aim is not to protect disruptive technologies from a hostile reaction of incumbents, but rather to prevent ISPs from engaging in disruptive technologies themselves. Criticism of Level 5B regulation is the key argument of this paper and so a more detailed elaboration of the argument is required.

Conventional wisdom suggests that CAPs should innovate (disruptively) in the area of content and application creation and ISPs should be active in the sphere of delivering the traffic. In reality, however, the activities of both these super-industries are interdependent. Hybridisation of the Internet implies direct expansion and interpenetration of CAPs in the area of electronic communication and that of ISPs in the sphere of creating or distributing content. The links between the two industries are even more obvious, when attention is shifted from inter-industry to intra-industry competition, namely when the conduct of ISPs influences competition within the CAPs industry and vice versa. It is precisely here where one can observe the first fallacy of hard Net Neutrality. The fallacy is based on the (wrong) assumption that inter-industry competition is more important than intra-industry one. This is done in keeping with the dominant view on the subsidiary role of intra-brand competition in comparison with the inter-brand one. But competition within an industry is an inter-brand competition itself, and thus the ability of ISPs to bring new dimensions to this competition is invaluable (though seldom explored or even articulated). At this point, another incorrect assumption should be deconstructed, namely, the view that all CAPs are united against the idea of soft (let alone hard) Net Prioritisation and that they firmly support the principles of hard (and of course soft) Net Neutrality. In some sense, they do indeed appear to be united but this unity has features surprisingly similar to cartel collusion. The introduction of traffic prioritisation would open enormous opportunities for inter-brand competition within the CAP industry. This competition would lead to new (disruptive) business models, enabling CAPs to compete within a completely new area of merit: the speed with which their content can be consumed by end-users. This new dimension of competition would be capable of rearranging the current state of affairs in the CAP business, by definition creating new winners and new losers. But rather than exploring these new commercial horizons, which would offer an excellent tool to reach new consumers and create new competitive advantages, each individual leading CAP has chosen a different path: they united in a proxy-war against these technological modifications (and by association against ISPs). With the help of human rights activists, political campaigners, industrial lobby 
groups and catchy slogans, something, which is an inherently commercial issue, has been presented to the public as an (ultimate) fight for free Internet. In other words, the key stakeholders understood that while a new reality would create numerous winners and losers within the CAP industry, the industry as a whole would be worse off, as Net Prioritisation would essentially imply a transfer of some net revenues generated by CAPs to ISPs.

It would be very difficult (though not impossible) to find arguments in support of hard Net Prioritisation (prohibited by Level 4 intervention). Indeed, targeted practices of speed downgrading, throttling and similar limitations associated with the 'free riding' problem, appear to be more disproportional, the more defensive and selective they are. Yet the campaigners for Net Neutrality succeeded in advocating for much stronger and much broader regulation, the regulation, which covers most aspects of soft Net Prioritisation (Level 5 intervention).

Another important clarification is necessary at this point: Level 5 intervention is not homogeneous either. It implies at least four paradigmatic layers of prohibition: layers $\mathrm{A}, \mathrm{B}, \mathrm{C}$ and $\mathrm{D}$.

Layer $\boldsymbol{A}$ intervention is the least controversial - it envisages that ISPs would operationalise their traffic management capacity at the expense of non-prioritised end users, simply offering higher speed to selected CAPs by lowering the speed for all others. However unrealistic this practice appears to be (especially in the areas with at least some meaningful competition between IPSs), and however anticompetitive it would be from the perspective of ex post antitrust (that is a Level 2 intervention), yet its explicit prohibition does not raise fundamental objections from most of the ISPs these days.

Layer $B$, by contrast, is particularly problematic. It implies the reverse scenario: most of the traffic remains unmanaged and all end-users receive their Internet access at normal speed. Some fraction of the whole traffic (for example 5\%), however, is allowed to be delivered at a higher speed. This premium speed service would be offered to CAPs (not end-users) for a fixed charge or percentage of the revenue generated as an outcome of such specific contracts between ISPs and CAPs. This mechanism has a potential to rearrange the way in which the Internet is consumed, and to reshuffle the strategic roles of the key stakeholders in the Internet as business. Leaving aside the political rhetoric of Net Neutrality, the motivation of CAPs to prevent this option is directed at this very point. So essentially, the economic essence of the Net Neutrality movement is centred precisely here. The following part of the essay analyses it in more detail. It will explain why shifting the regulatory cursor from Level 5B (where it is now) to Level 5A might increase competition, boost (disruptive) innovation, contribute to the benefits of consumers (both in terms of welfare and choice), and help to address antitrust problems associated with 
the abusive conduct of many disruptive innovators on the CAP side of the business.

Layer $\boldsymbol{C}$ and Layer $\boldsymbol{D}$ are less controversial. They constitute instances, in which proponents of soft Net Prioritisation already secured at least a partial victory in Europe. Layer C concerns the ability of ISPs to provide some priority as regards their own content or content streamed by ISPs (or integrated companies) themselves. Layer D leaves room for ISPs to provide some prioritisation to such specialised services as telemedicine, driverless cars and other highly innovative and highly specialised models. Some of the traffic management necessary for the delivery of such services is currently envisaged at an EU regulatory level.

\section{EU Net Neutrality Rules}

The Possible formats of Net Neutrality have been debated in Europe for over a decade (Maniadaki, 2015, pp. 35-36; Alexiadis and Cockcroft, 2014). On 25 November 2015, EU Telecom Single Market (hereinafter; TSM) Regulation was adopted. ${ }^{3}$ The Body of European Regulators for Electronic Communications (BEREC) is required to monitor compliance of individual Member States with the requirements of the TSM Regulation.

The TSM Regulation puts forward 'common rules to safeguard equal and non-discriminatory treatment of traffic in the provision of internet access services and related end-users rights' (Article 1). These common rules can be subject to some traffic management limitations, related mainly to effective technical management of the network. ${ }^{4}$

3 Regulation (EU) 2015/2120 of the European Parliament and of the Council of 25 November 2015 laying down measures concerning open internet access and amending Directive 2002/22/EC on universal service and users' rights relating to electronic communications networks and services and Regulation (EU) No 531/2012 on roaming on public mobile communications networks within the Union (Text with EEA relevance), OJ L 310, 26.11.2015, p. 1-18.

${ }^{4}$ Article 3(3) of the TSM Regulation: '[ISPs can implement] reasonable traffic management measures. In order to be deemed to be reasonable, such measures shall be transparent, non-discriminatory and proportionate, and shall not be based on commercial considerations but on objectively different technical quality of service requirements of specific categories of traffic.

Such measures shall not monitor the specific content and shall not be maintained for longer than necessary. Providers of internet access services shall not engage in traffic management measures going beyond those set out in the second subparagraph, and in particular shall not block, slow down, alter, restrict, interfere with, degrade or discriminate between specific content, applications or services, or specific categories thereof, except as necessary, and only for as long as necessary'. 
In other words, the TSM Regulation provides explicit and unequivocal support for soft Net Neutrality rules (Level 4), ${ }^{5}$ but not all elements of hard Net Neutrality rules (Level 5) are protected by it. In particular, it explicitly reserves the room for Level 5D (specialised services) Net Prioritisation ${ }^{6}$, as well as offering some implicit toleration towards Level 5C services (prioritisation of content/application offered by ISPs' own platforms). It also enables reasonable traffic management in the case of public policy exceptions related to the integrity and security of the network and the eventual avoidance of its congestions. For obvious reasons, these exemptions go beyond the scope of this discussion.

But even a creative interpretation of some provisions of the TSM Regulation leaves no room for Level 5B of Net Prioritisation - the level, an open recognition of which would entail a paradigmatic shift in the business of the Internet, and which constitutes the central argument of this essay, which advocates for its necessity. Level $5 \mathrm{~A}$ is protected in full and the essay offers no amendment in this respect.

\section{Parallel reality: a business model without Net Neutrality rules}

As became obvious in the introduction, this essay does not share the popular belief that the Net Neutrality movement is motivated by political slogans about Internet democracy and universal access. Distancing ourselves from this appealing and viral rhetoric, we can see two very powerful and mutually dependent industries: ISPs and CAPs, coming to grips over the future architecture of the Internet and over the role each industry will play there. They confront each other in a very dynamic time, in which the market positions they manage to secure today will define their economic power for decades.

5 Recital (11) of the TSM Regulation: 'Any traffic management practices which go beyond such reasonable traffic management measures, by blocking, slowing down, altering, restricting, interfering with, degrading or discriminating between specific content, applications or services, or specific categories of content, applications or services, should be prohibited.'

${ }^{6}$ Article 3(5) of the TSM Regulation: 'Providers [...] shall be free to offer services other than internet access services which are optimised for specific content, $[\ldots]$ where the optimisation is necessary in order to meet requirements of the content, applications or services for a specific level of quality. Providers of electronic communications to the public, including providers of internet access services, may offer or facilitate such services only if the network capacity is sufficient to provide them in addition to any internet access services provided. Such services shall not be usable or offered as a replacement for internet access services, and shall not be to the detriment of the availability or general quality of internet access services for end-users.' 
Under the current format of the Internet, content from CAPs is delivered to end-users by ISPs in, essentially, a non-differentiated way. This implies that CAPs compete for end-users between themselves. ISPs do not participate in this process. They compete for end-users on quality and price only at the users' last mile. They are not allowed to compete at the end-users first mile. Powerful triggers of competition, such as the offer of premium speed traffic to selected CAPs, have been artificially removed from the competitive options of ISPs by explicit Net Neutrality regulation. This situation is pathological. In its stylised form it would be similar to prohibiting restaurants to compete with each other using the Google Maps service as it 'infringes' 'Restaurant Neutrality' principles.

Without such rules many ISPs would be able to offer CAPs an option of delivering their content to end-users at higher speed, which would obviously strengthen the market position of those CAPs in the click-and-watch Internet universe. Such a service would not be discriminatory if only a tiny proportion (for example 5\% of all traffic processed by the ISP) were eligible for such differentiation. By analogy, flying with business-class is non-discriminatory for the remaining passengers if only a tiny proportion of seats is envisaged for this option (it would become discriminatory if a dominant airline would sell business class tickets as the default option). Reductio ad Absurdum, higher prices, paid by end-users for higher speed at the 'last mile' could also have some impact on neutrality, but nobody is labelling this as discriminatory. But the same optional practice done by CAPs is seen as the utmost evil of the Internet.

A counterargument to this scenario would be a hypothesis that premium speed would be used only by top CAPs, which would make the gap between them and the rest of CAPs even bigger. First of all, the very idea that regulatory intervention can be used to shape the exact format of a particular industry requires robust justification. The burden of proof is on the proponents of Net Neutrality. Second, the premium speed option could be regularly accessed by newcomers, which would lower barriers to entry and can be generally seen as procompetitive. Third, even if accepting the assumption that premium speed will be primarily used by powerful CAPs, they would be mainly using this tool in their competition between themselves (and not between them and smaller CAPs). This would encourage (disruptive) innovation, increase competition and contribute to positive viewer experiences. Fourth, even if the format is inaccessible for smaller CAPs, these CAPs would still be able to deliver their content at normal (non-premium) speed as is the case with Net Neutrality rules. Fifth, the availability of such option would have a positive impact on (disruptive) innovation techniques used also by ISPs, as they would transform themselves from a 'dumb pipe' mission to a proactive Internet industry. 
From the perspective of antitrust enforcers and sector specific regulators disruptive innovation is a double-edged sword. On one hand, we all know that innovation is an inevitable component of human progress and prosperity, that most of our policies are designed to protect and encourage innovation. On the other hand, we also know that many disruptive innovators cause competition-related problems. Another incarnation of Bork's antitrust paradox: the more powerful/successful the innovator becomes the higher potential he gains to harm competition.

In a classical Net Neutrality rhetoric, proactive ISPs are seen as obstacles for innovation. The classic rent-seekers vs. free-riders dilemma has been solved by regulators in favour of the latter. But the CAPs did not stop at this soft Net Neutrality imperative (prohibition of defence against free-riding), going further, preventing ISPs from incentives to use their natural competitive advantage: traffic speed; to innovate in the area of their specialisation. Disruptive innovations in the sector of ISPs have been sacrificed for the benefits of disruptive innovations in the sector of CAPs. Enabling ISPs to take a more proactive position would boost the hybridisation of platforms and means of content delivery.

What appears to be particularly striking is that CAPs criticise soft Net Prioritisation rules despite the fact that these rules would enable another important element of competition between CAPs themselves, as the ability to deliver content to end-users at higher speed is a very appealing marketing tool and a very powerful factor in designing new commercial models to the detriment of competitors and to the benefit of consumers. Surprisingly (?), instead of exploiting these options in trying to be the first, CAPs as an industry has opted for a radical opposition to such technological improvement, using influential lobby groups to shift regulatory attention to the illusionary problems of human rights and scaremongering the public with aggressive political campaigns for 'Internet freedom'.

Schematically, such behaviour among CAPs is very similar to the conduct of members of cartels, who opt for joining their efforts in achieving benefits for the industry as a whole to the detriment of competition between different members of the industry. The surprising unity of CAPs in rejecting such a powerful instrument of competition within the industry can be explained by their coordinated action. Something which is essentially an important factor of intra-industry competition between CAPs has been re-interpreted by presenting it as a battle between CAP and ISP industries (which is also true... half-true). 


\section{Conclusion}

This essay argues in favour of loosening the regulatory mechanism of Net Neutrality from Level 5B to Level 5A (the specific nature of these levels has been discussed in Section II of the paper). Soft Net Neutrality (5A) rules suffice to protect the CAPs industry from the discriminatory actions of ISPs. Hard Net Neutrality (5B and below) rules are too bold and unreserved. Hard Net Neutrality discourages ISPs from (disruptive) innovation; prevents end-user choice, disallowing access to premium content at premium speed; and it infringes competition between CAPs on the grounds of speed with which their content is delivered to end-users. Overall, hard Net Neutrality rules provide a disproportionally beneficial regulatory environment for one industry (CAPs) at the cost of another (ISPs), disentangling the latter's ability to innovate disruptively in a market with very high economic, technological and social potential. The essay further provides differentiation of Level 5 regulatory intervention, explaining that the economic gist of the Net Neutrality debate is focused between Layers A and B of Level 5, namely, between traffic discrimination vs. traffic prioritisation. Traffic is differentiated in a discriminatory way (Layer A) when premium speed is granted to the detriment of most of the end-users. Such a practice is correctly prohibited. Traffic is differentiated in a form of prioritisation when only a tiny fraction (for example 5\%) is offered by ISPs to CAPs at a special rate. Such practice does not affect network capacity or the general speed of all end-users, who consume the remaining $95 \%$ of traffic, as this mode of provision is, in turn, primarily an outcome of ISPs' incentive to invest and innovate, derived from their ability to generate additional profits and explore new markets. Premium speed charge is offered not to end-users, but to CAPs, which encourages competition within this industry.

Even if CAPs passed on some of their additional costs to consumers, they would do it in a competitive environment; consumers will always be able to opt out of premium speed by simply not downloading the relevant content; consumers would get in return 'premium' speed; and finally, those CAPs who chose this model would be very likely to generate additional profits by gaining higher market share. As a result, the necessity of passing any substantial costs on to consumers would remain hypothetical rather than real. Even in the worst case scenario, these costs would be fractional and incomparably smaller than the benefits generated for end-users and society as a whole. Most consumers would be unaffected. Most of those affected would be affected positively. ISPs would get regulatory permission (sic!) to innovate. Competition within the CAP industry for quicker delivery of their content and applications to end-users would be incentivised (if not created from scratch) - these are the 
quite likely consequences of shifting the regulatory cursor from Level $5 \mathrm{~B}$ to Level 5A.

Even a symbolic number as regards prioritised traffic, such as $5 \%$, is capable of stimulating ISPs to explore this business model and to trigger competition in the CAP industry. This is a sector of the economy that, until recently, has been considered by regulators as deserving preferential treatment, and which has increasingly demonstrated features surprisingly similar to other industries, which competition enforcers and regulatory authorities deal with on a regular basis.

The essay is based on a conceptual analysis. The suggested number of 5\% is taken as a symbol of the necessity to leave at least some room for this business model open. If regulators are unhappy with $5 \%$, they can move it to $1 \%$ of the traffic. Disruptive innovations take place in all spheres of human activity. The law is not immune to this process. Allocating even a tiny regulatory space for this model could test its feasibility and effectiveness. The scope can always be managed by regulators accordingly. What is important is not to abandon this business model outright. Such a complete prohibition of Level 5B is disproportional, unjustified and based only on successful policy activism on the part of this complex side, the part (however innovative it appears to be), which in this particular instance has chosen to sacrifice competition for stability, a choice in itself very suspicious from the perspective of competition law and policy. If it succeeds, this model could also remedy some of the antitrust related problems in the area of CAP as it would create new challenges for most of the dominant CAPs. Furthermore, this remedy would be generated by genuine market forces streaming from a different industry, in essence, allowing the market to correct regulatory errors.

\section{Literature}

Alexiadis, P. and Cockcroft, C. (2014). Net Neutrality in Europe: Reconciling the Irreconcilable, Financier Worldwide, June.

Maniadaki, K. (2015). EU Competition Law, Regulation and the Internet. The Case of Net Neutrality, Alphen aan den Rijn: Wolters Kluwer Law \& Business. 